\title{
Detection and Prevalence Rate of American Cockroaches (Periplaneta americana) Bacterial Infections in Human Dwellings
}

\author{
Hamid Kassiri ${ }^{1, *} ;$ Ali Kasiri $^{2}$; Anvar Quaderi ${ }^{1}$ \\ ${ }^{1}$ Department of Medical Entomology and Vector Control, Ahvaz Jundishapur University of Medical Sciences, Ahvaz, IR Iran \\ ${ }^{2}$ Department of Ophthalmology, Ahvaz Jundishapur University of Medical Sciences, Ahvaz, IR Iran \\ *Corresponding author: Hamid Kassiri, Department of Medical Entomology and Vector Control, Ahvaz Jundishapur University of Medical Sciences, Ahvaz, IR Iran. Tel:+98-6113738269, \\ Fax:+98-6113738282, E-mail: hamid.kassiri@yahoo.com
}

Received: March 4, 2014; Revised: May 10, 2014; Accepted: May 23, 2014

\begin{abstract}
Background: In hospitals, it has been clarified that Periplaneta americana can operate as possible vectors of nosocomial infections, chiefly for the transmission of drug-resistant bacteria. Also, these domestic insects have a role in transmitting food-borne diseases. The bacterial loads of these insects have been reported as seven million in each excretion dropping and up to 14 million on their cuticle. Their presence decreases human health and sanitary standards.

Objectives: This descriptive study was carried out to confirm that Periplaneta americana L. (Dictyoptera; Blattidae) carry pathogenic bacteria in residential areas, by bacteriological analysis of the cuticles of this insect.

Materials and Methods: In this research we caught 25 American cockroaches from human dwelling localities of Ahvaz province during 2008 and 2009. Cockroaches were collected using sticky traps, vacuum cleaners and direct collection. The collected cockroaches were brought to the laboratory and were identified as P. americana. They were examined for the presence of bacteria on their external surfaces using specific standard methods for bacterial infection.

Results: One hundred percent of cockroaches had bacterial infections. Culturing of the external parts wash homogenates resulted in the isolation of Escherichia coli, Proteus, Serratia, Klebsiella, Enterobacter, Pseudomonas, Staphylococcus aureus, Streptococcus, Enterococcus, Citrobacter, Micrococcus.
\end{abstract}

Conclusions: The results showed that $P$. americana is a possible reservoir and potential vector of some pathogenic agents.

Keywords:Periplaneta americana; Bacterial Infection; Iran

\section{Background}

Cockroaches have distributed all over the globe and about 4000 species have been identified. Domestic cockroaches such as Periplaneta americana, Blattella germanica, Blatta orientalis, Periplaneta australis and Supella longipalpa are frequently recorded in Iran. The American cockroach is a large insect and the adult body length is about 1-1/2 inches $(38 \mathrm{~mm})$. The adult is a shiny reddish brown to dark brown and has a yellow edge on the protergum. Adult P. americana have four wings and occasionally fly. This species is a synanthropic species, yet they can also propel indoor areas and live in human occupied enviroments (1-5). Members of this species generally live in warm and humid structures but may survive in drier regions if they have availability to water. American cockroaches are also known to transport pathogenic bacterial agents in their intestine and on their body surface. These germs may be transferred to food and other items that come in contact with the cockroaches. Various bacteria universally associated with these insects are recognized to inure diarrhea, dysentery and food intoxication in humans. Cockroaches have been associated with an outbreak of dysentery. Shigella dysenteriae, Salmonella typhi and toxigenic strains of Escherichia coli can be retained in the gut of cockroaches for up to several days. Thus, these insects also play a role in transmitting food-borne diseases $(6,7)$. Based on previous investigations, bacteria species may stay alive on the cockroaches' cuticle for a few days (8). Salmonella is stable in cockroaches for more than 10 months (9). Periplaneta americana also produce allergens on their bodies and in their excrement. American cockroaches have been implicated as a possible reason for childhood asthma and allergic dermatitis (10-13). Multiple studies have demonstrated that cockroaches living near human environments were significant vectors of etiological agents and all groups of possible pathogens such as, protozoans, bacteria, helminthes and viruses (14). Different species of bacteria of public health significance have been isolated from Periplaneta americana, such as Staphylococcus aureus, Streptococcus spp., Enterobacteriaceae, Pseudomonas aeruginosa, and so on. Cockroaches captured in hospitals and houses have been found to harbor multi-drug resistant bacteria (3).

\section{Objectives}

The aim of this investigation was therefore to assess

Copyright ( 2014 , Infectious Diseases and Tropical Medicine Research Center; Published by Kowsar. This is an open-access article distributed under the terms of the Creative Commons Attribution-NonCommercial 4.0 International License (http://creativecommons.org/licenses/by-nc/4.0/) which permits copy and redistribute the material just in noncommercial usages, provided the original work is properly cited. 
the role of American cockroaches as potential carriers of pathogenic bacteria and relative abundance of bacteria carried by this species in residential areas of Ahvaz province, Southwest Iran.

\section{Materials and Methods}

This descriptive study was conducted during 2008 and 2009 at the Ahvaz Jundishapur University of Medical Sciences, Ahvaz, Iran. A total of 25 cockroaches were collected using sticky traps, vacuum cleaners and hand catch methods from human dwellings, to determine the presence of pathogenic bacterial agents on their bodies. Sterile hand-gloves were used for sampling. The collected cockroaches were transferred by separate clean and sterile tubes. Next, samples were transported to the laboratory. The instruments were sterilized with alcohol and flame. Trapped cockroaches were frozen at $0^{\circ} \mathrm{C}$ for 10 minutes. Cockroaches were identified using reliable taxonomic keys. Each of the samples was washed in a sterile glass containing $2 \mathrm{~mL}$ of sterile saline and the resulting suspension was cultured. Bacteria were isolated and identified from American cockroach samples using standard techniques for bacterial infection. All specimens were cultured for growing bacteria on blood agar, MacConkey agar media and other selective bacterial media. The microorganisms were identified using necessary differential and biochemical tests.

\section{Results}

Twenty-five American cockroaches were randomly selected and detected by bacteriological examinations. Medically important bacteria were isolated from the external surface of $100 \%$ of cockroaches. This finding suggests that almost all the cockroaches in the residential environments carry medically important pathogenic bacteria. Eleven bacterial species were isolated from cockroaches. The most common detected bacteria were found to be Escherichia coli, Staphylococcus aureus, Proteus spp., Klebsiella spp., Citrobacter spp. and Enterobacter spp. where $100 \%, 72 \%, 60 \%, 60 \%, 56 \%$ and $52 \%$ of cockroaches were infected by these species, respectively. The minimum contamination was by Serratia spp. (20\%), Micrococcus spp. (32\%) and Enterococcus spp. (40\%), respectively. The other extracted bacteria in this research were Psudomonas spp. (44\%) and Sterptococcus spp. (48\%). Most of the bacterial isolates from the external surface of cockroaches were gram-positive. All of American cockroaches examined in this research were infected with at least one bacterium.

\section{Discussion}

All cockroaches trapped in this research were identified as Periplaneta americana. American cockroaches are often found in close association with humans. They are numerous in cities and villages where unsanitary situations dominate. Due to their association with residents, cockroaches can contact and obtain pathogenic agents. Pathogens can then be mechanically transmitted to human populations. The presence of cockroaches in human dwellings is never favorable, and should an issue of concern. They are also a risk factor for human sanitation and low level of health. The isolation of Escherichia coli, Staphylococcus aureus, Proteus spp., Klebsiella spp., Citrobacter spp., Enterobacter spp., Serratia spp., Micrococcus spp., Enterococcus spp., Psudomonas spp. and Sterptococcus spp. from this cockroach species showed that household pests could be a health challenge to humans. Also, this finding indicated the potential role of cockroaches in distributing pathogens in human communities. Some of the bacterial isolates are known to be pathogenic while others are either opportunistic or play roles in food spoilage. The finding of $E$. coli among cockroaches means that these insects have been in contact with human feces or feces-contaminated material. The bacterial species most repeatedly isolated from cockroaches were gram-negative bacilli, particularly in the Family of Enterobacteriaceae. In fact, Blattaria are considered as an ecological niche of some Enterobacteriaceae. They can cause urinary tract infections, wound infections, gastroenteritis, sepsis, urinary, biliary and peritoneal infections and pneumonia $(7,15)$. Isolation of gram-negative bacilli such as Pseudomonas spp., Serratia spp., E. coli, Klebsiella spp., Proteus spp., Citrobacter spp. and Enterobacter spp. from the external surfaces in this study agrees with previous reports by Akinjogunla et al. (2), Feizhaddad et al. (15), Kassiri et al. (11), Nejati et al. (8) and Lamiaa et al. (6). Furthermore, in this study different species of gram-positive bacteria (Micrococcus spp., Enterococcus spp., Staphylococcus aureus and Streptococcus spp.) were isolated from cockroaches. Results of Chitsazi's studies showed that cockroaches were contaminated by four gram-positive bacteria species, including Staphylococcus aureus, Enterococcus spp., Enterococcus spp. and Streptococcus spp $(16,17)$. These results are consistent with the results of the present study. In conclusion, to reduce the risk of transmission of various pathogens, the application of appropriate control methods should be considered to manage populations of cockroaches in human dwellings. People should be aware of the potential pathogenic transmission by cockroaches and should keep kitchens, bathrooms and toilets clean and prevent infestation of cockroaches in their houses.

\section{Acknowledgements}

This project (No. 88S.8) was conducted in collaboration with the Deputy for Research of Ahvaz Jundishapur University of Medical Sciences, Ahvaz, Iran. The researchers gratefully thank those who assisted in trapping of cockroaches in their houses.

\section{Authors' Contributions}

Hamid Kassiri developed the original idea and the protocol, abstracted and analyzed the data. Hamid Kas- 
siri and Ali Kasiri wrote the manuscript. Anvar Quaderi contributed to the development of the protocol and abstracted the data.

\section{Funding/Support}

This study was supported in part by the Research Affairs of Ahvaz Jundishapur University of Medical Sciences, Ahvaz, Iran.

\section{References}

1. Salehzadeh A, Tavacol P, Mahjub H. Bacterial, fungal and parasitic contamination of cockroaches in public hospitals of Hamadan, Iran. J Vector Borne Dis. 2007;44(2):105-10.

2. Akinjogunla OJ, Odeyemi AT, Udoinyang EP. Cockroaches (periplaneta americana and blattella germanica): reservoirs of multi drug resistant (MDR) bacteria in Uyo, Akwa Ibom State. Scientific J Biol Sci. 2012;1(2):19-30.

3. Bouamamaa L, Sorlozano A, Laglaoui A, Lebbadi M, Aarab A, Gutierrez J. Antibiotic resistance patterns of bacterial strains isolated from Periplaneta americana and Musca domestica in Tangier, Morocco. J Infect Dev Ctries. 2010;4(4):194-201.

4. Nasirian H. An overview of German cockroach, Blattella germanica, studies conducted in Iran. PakJ Biol Sci. 2010;13(22):1077-84.

5. Vazirianzadeh B, Dehghani R, Mehdinejad M, Sharififard M, Nasirabadi N. The First Report of Drug Resistant Bacteria Isolated from the Brown-Banded Cockroach, Supella longipalpa, in Ahvaz, South-western Iran. J Arthropod Borne Dis. 2013;8(1):53-9.

6. Lamiaa B, Lebbadi M, Ahmed A. Bacteriological analysis of Periplaneta americana L.(Dictyoptera; Blattidae) and Musca domestica L.(Diptera; Muscidae) in ten districts of Tangier, Morocco. Afr Jiotechnol . 2007;6(17):2038-42.

7. Chaichanawongsaroj N, Vanichayatanarak K, Pipatkullachat T, Polrojpanya M, Somkiatcharoen S. Isolation of gram-negative bacteria from cockroaches trapped from urban environment. Southeast Asian J Trop Med Public Health. 2004;35(3):681-4.

8. Nejati J, Keyhani A, Moosa-Kazemi SH, Mohammadi M, Mahjoob M, Boostanbakhsh A. Cockroaches' bacterial infections in wards of hospitals, Hamedan city, west of Iran. Asian Pac J Trop Dis. 2012;2(5):381-4.

9. Fathpour H, Emtiazi G, Ghasemi E. Cockroaches as Reservoirs and Vectors of Drug Resistant Salmonella spp. Iran Biomed J. 2003;7(1):35-8.

10. Kassiri H, Kassiri A, Kazemi S. Investigation on American cockroaches medically important bacteria in Khorramshahr hospital, Iran. Asian Pac J Trop Dis. 2014;4(3):201-3.

11. Kassiri H, Kazemi S. Cockroaches [Periplaneta americana (L.), Dictyoptera; Blattidae] as carriers of bacterial pathogens, Khorramshahr County, Iran. Jundishapur J Microbiol. 2011;5(1):320-2.

12. Farhoudi A, Pourpak Z, Mesdaghi M, Chavoshzadeh A, Kazemnejad $Z$. The study of cockroach allergy in Iranian children with asthma. Acta Med Iran. 2003;41(3):150-5.

13. Behmanesh F, Shoja M, Khajedaluee M. Prevalence of aeroallergens in childhood asthma in Mashhad. Macedonian J Med Sci. 2010;3(3):295-8.

14. Tachbele E, Erku W, Gebre-Michael T, Ashenafi M. Cockroach-associated food-borne bacterial pathogens from some hospitals and restaurants in Addis Ababa, Ethiopia: Distribution and antibiograms.J Rural Trop Public Health. 2006;5:34-41.

15. Feizhaddad MH, Kassiri H, Sepand M, Ghasemi F. Bacteriological survey of American cockroaches in hospitals. Middle East J Sci Res. 2012;12(7):985-9.

16. Chitsazi S, Moravvej G, Naderi Nasab M. [A survey on the bacterial and fungal contamination of German cockroaches in Mashhad Imam-Reza hospital during 2009-2010]. J Kashan U Med Sci. 2013;16(6):576-84.

17. Chitsazi S, Moravvej G, Naderi Nasab M. [A survey on the bacterial and fungal contamination of German cockroaches in a hospital, student accommodations and houses in Mashhad City]. Iran J Med Microb. 2012;6(10):16-26. 